\title{
CARACTERIZAÇÃO DOS RIZOMAS FILHOS E DA \\ FÉCULA DO MANGARITO (Xanthosoma mafaffa Schott) E ELABORAÇÃO DE FILMES BIODEGRADÁVEIS
}

\author{
RAFAELA DE ÁVILA* \\ DIEGO PALMIRO RAMIREZ ASCHERI ${ }^{* *}$ \\ JOSÉ LUIS RAMÍREZ ASCHERI ${ }^{* * *}$
}

\begin{abstract}
No presente trabalho foram determinadas as propriedades físicas e químicas do rizoma filho e da fécula do mangarito e algumas propriedades dos filmes biodegradáveis da fécula e glicerol. Dos rizomas filho foram determinados a massa, os diâmetros maior e menor e a composição química. Determinou-se a composição química e o valor calórico da fécula extraída, suas propriedades térmicas e de pasta. De seus grânulos se analisaram a morfologia e o tamanho. Os filmes foram elaborados pela técnica casting, variandose a quantidade do glicerol e a massa de solução filmogênica de acordo com delineamento fatorial central composto. Dos filmes obtidos foram estudadas a aparência, a espessura, a solubilidade e a permeabilidade. Aplicou-se análise de variância para modelo polinomial de segundo grau e a função desejabilidade para a sua otimização. Obteve-se a massa média dos rizomas filho de $3,5 \mathrm{~g} \mathrm{e}$ diâmetros maior e menor de 23 e $15 \mathrm{~mm}$, respectivamente, sendo constituídos principalmente de fécula com grânulos arredondados de $12,5 \mu \mathrm{m}$ de diâmetro. A pasta da fécula apresentou boa estabilidade frente ao calor sob agitação mecânica e grande tendência à retrogradação. Considerando os fatores desejáveis de alta solubilidade e de baixas permeabilidade e espessura, os filmes produzidos com $10 \%$ de glicerol e $24,73 \mathrm{~g}$ de solução filmogênica atenderiam melhor essas características.
\end{abstract}

PALAVRAS-CHAVE: Xanthosoma mafaffa Schott; PROPRIEDADES FÍSICO-QUÍMICAS E FUNCIONAIS; FILMES BIODEGRADÁVEIS; AMIDOS.

* Engenheira de Alimentos, Mestre em Engenharia Agrícola, Universidade Estadual de Goiás (UEG), Anápolis, GO (e-mail: rafaeladeavila@gmail.com).

** Engenheiro de Alimentos, Doutor em Engenharia Agrícola, UEG, Anápolis, GO (e-mail: ascheridpr@gmail. com).

*** Engenheiro de Alimentos, Doutor em Tecnologia de Alimentos, Pesquisador da Embrapa Agroindústria de Alimentos, Guaratiba, Rio de Janeiro, RJ (e-mail: cwpiler@ctaa.embrapa.br, ascheri@ctaa.embrapa.br). 


\section{INTRODUÇÃo}

O amido é encontrado em grande concentração na natureza, principalmente em plantas, grãos de cereais, tubérculos, raízes e leguminosas (LEONEL e CEREDA, 2002). Por seu peculiar uso, as indústrias de alimentos estão interessadas na identificação e no desenvolvimento de espécies que produzam amidos nativos com características físico-químicas e funcionais especiais para manter e/ou realçar as propriedades dos seus produtos, mesmo após estocagem e refrigeração (BOBBIO e BOBBIO, 2003). Essa macromolécula pode, entre outras funções, facilitar o processamento, melhorar a textura, servir como espessante, fornecer sólidos em suspensão e proteger os alimentos durante o processamento.

As embalagens biodegradáveis à base de amido são as mais estudadas e empregadas, respondendo por 85 a $90 \%$ do mercado total dos materiais biodegradáveis. Além de ser renovável e biodegradável, o amido tem baixo custo, alta disponibilidade e propriedades de formar filmes e espumas (ALVES e TOMÁS, 2003; CARR et al., 2006). Entretanto, usam-se mais habitualmente para essa finalidade amidos de culturas destinadas à alimentação humana (como mandioca, milho, arroz e outros cereais), o que acaba gerando competição com o caráter alimentar. Essa competição e a evolução do setor alimentar, maior consumidor de amido nativo ou modificado, estão gerando investimentos em pesquisas visando a identificação de novos amidos nativos que apresentem propriedades diferenciadas.

O mangarito (Xanthosoma mafaffa Schott), planta herbácea sem caule aéreo, apresenta rizoma subterrâneo principal (mãe ou primário) com brotações laterais (rizomas filhos ou secundários) e várias folhas grandes brotando do rizoma principal. Pertencente à família Araceaem, é originário da região centro-americana que engloba as Américas Central e do Sul. O mangarito também é conhecido como tannia, tiquisque, malangay e no Brasil como mangará, taioba portuguesa e mangareto, sendo denominado pela população Guarani de tayaó. Trata-se de uma das espécies mais energéticas, constituída prioritariamente por fécula. Os rizomas filhos, com pequenas dimensões, são pouco atrativos para a utilização culinária e consequentemente tem baixo valor comercial (COSTA et al., 2008; LEITE et al., 2007).

O amido ou fécula pode ser utilizado para a elaboração de filmes comestíveis de acordo com suas características físico-químicas, produzindo filmes com propriedades funcionais diferenciadas, principalmente, aqueles com rápida biodegradação, tornando-os vantajosos frente às embalagens de origem petroquímicas.

O presente trabalho teve por objetivo principal estudar as propriedades físicas e químicas do rizoma filho e da fécula de mangarito e a elaboração de filmes biodegradáveis à base da fécula com adição de glicerol e da massa de solução filmogênica.

\section{MATERIAL E MÉTODOS}

Realizou-se o experimento nos laboratórios de Química e de Engenharia Agrícola da Unidade Universitária de Ciências Exatas e Tecnológicas (UNUCET) da Universidade Estadual de Goiás (UEG), localizada em Anápolis (GO) e no laboratório de Reologia da Embrapa Agroindústria de Alimentos (EMBRAPA/RJ), no período de julho de 2009 a setembro de 2010.

Os rizomas filhos foram cedidos pela Fazenda Veadinho, localizada no perímetro rural do município de Uberlândia/MG (Latitude: $18^{\circ} 56^{\prime}$ e $59,140^{\prime \prime}$ ao sul e longitude $48^{\circ} 03^{\prime}$ e 57,833 " a Oeste). A colheita dos rizomas ocorreu no mês de julho de 2009 quando suas folhas já estavam secas e senescentes, após nove meses de cultivo. Os rizomas filhos foram transportados em temperatura ambiente, em sacos plásticos de ráfia (que permitem a circulação do ar) até a UNUCET, permanecendo armazenados à temperatura ambiente até a extração da fécula.

Os rizomas filhos foram pesados, selecionados, lavados em água corrente e secos em 
temperatura ambiente. Efetuou-se a caracterização física dos rizomas, em triplicata, mediante a pesagem e mensuração da amostra, obtida por meio de quarteamento até atingir 100 rizomas (INSTITUTO ADOLFO LUTZ, 2008). A pesagem e a mensuração foram realizadas com auxílio de balança semianalítica (Marte, AL 500, Santa Rita do Sapucaí, MG, Brasil) e de paquímetro digital com precisão de $150 \mathrm{~mm}$ (Digimess, São Paulo, SP, Brasil), respectivamente.

Triturou-se parte dos rizomas filhos com casca em liquidificador industrial LQ (Visa, Brusque, SC, Brasil), sendo coletadas amostras para análise da sua composição química. Os rizomas restantes, utilizados para a extração e purificação da fécula, foram moídos em macro moinho de rotor circular com facas móveis e fixas (Marconi, MA-580, Piracicaba, SP, Brasil) até passarem por peneira de malha contendo furos de $1 \mathrm{~mm}$ de diâmetro. Separou-se a fécula da massa leitosa, mediante peneiragens sucessivas, usando peneiras de malhas finas com furos de diferentes diâmetros $(150,75,45$ e $38 \mathrm{~mm})$, seguidas de decantação em baldes plásticos. A fécula obtida foi lavada com álcool etílico para remoção de substâncias gordurosas, filtrada a vácuo e seca em estufa com circulação e remoção de ar (Marconi, MA035, Piracicaba, SP, Brasil) a $45^{\circ} \mathrm{C}$ até peso constante, sendo resfriada à temperatura ambiente e acondicionada em frascos plásticos até sua utilização.

Determinou-se a composição química dos rizomas e da fécula em base úmida (bu) e seca (bs). A umidade, o extrato etéreo e as cinzas foram analisados segundo métodos do Instituto Adolfo Lutz (2008). Para as determinações dos açúcares totais, não redutores e redutores e fibra bruta usou-se a metodologia da Association of Official Analytical Chemists (2000). Determinou-se o teor proteico das amostras pela técnica microkjedahl de acordo com o Ministério da Agricultura, Pecuária e Abastecimento (BRASIL, 2009). Os carboidratos foram calculados por diferença, subtraindo-se de 100 os valores encontrados para umidade, proteínas, extrato etéreo e cinzas. Calculou-se o valor energético total multiplicando as porcentagens totais de lipídios, proteínas e carboidratos de cada amostra pelos seus valores calóricos respectivos: $9 \mathrm{kcal}, 4 \mathrm{kcal} \mathrm{e} 4 \mathrm{kcal}$ (fatores de conversão de Atwater). Para a análise do teor de amido adaptou-se a metodologia de digestão ácida em microondas de Cereda, Daiuto e Vilpoux (2004), substituindo o micro-ondas por autoclave para digestão. Após atingir $1 \mathrm{Kgf} \mathrm{cm}^{-2}$ marcou-se o tempo de $20 \mathrm{~min}$.

A morfologia e o tamanho dos grânulos da fécula foram analisados segundo a técnica descrita por Vigneau et al. (2000), com modificações. Três amostras de fécula, coletadas com fio de platina, foram misturadas e colocadas sobre lâmina de vidro com uma gota de lugol e, posteriormente, coberta com lamínula. Repetiu-se o processo, porém sem o lugol. As lâminas foram observadas em microscópio óptico LEICA DME, tipo EC3 (Wetzlar, Alemanha), sendo capturadas, selecionadas e analisadas dez imagens de cada amostra (totalizando 60 imagens) pelo software Leica Application Suite LAS EZ v. 2.0.0 (LEICA..., 2010), o qual possibilita a visualização clara do formato e permite estimar o tamanho dos grânulos da fécula.

Determinou-se a viscosidade de pasta em RVA (Rapid Visco Analyzer 4, Newport Scientific PTY LTD, Sydney, Austrália), conforme sua metodologia para materiais amiláceos. Preparou-se a solução com $3 \mathrm{~g}$ de fécula, com umidade corrigida para 14\% (bs), e adicionou-se água destilada até o peso final de $28 \mathrm{~g}$ (ASCHERI et al., 2006). A temperatura inicial de $25^{\circ} \mathrm{C}$ foi aumentada, gradualmente até $95^{\circ} \mathrm{C}$, sendo mantida constante por $3 \mathrm{~min}$. Realizou-se o resfriamento também gradualmente até a temperatura final de $25^{\circ} \mathrm{C}$. Do perfil de viscosidade analisaram-se a viscosidade máxima, definida como o valor da viscosidade (em centipoise, $\mathrm{cP}$ ) no ponto máximo da curva, obtido durante o ciclo de aquecimento; a temperatura e o tempo de gelatinização, definidos como a temperatura $\left({ }^{\circ} \mathrm{C}\right)$ e o tempo $(\mathrm{min})$ necessários para atingir o ponto máximo de viscosidade de pasta.

Efetuou-se a análise calorimétrica da fécula em calorímetro diferencial de varredura DSC Q200 (TA Instruments, New Castle, EUA) de acordo com a metodologia de Fakirov et al. (1997).

Para a elaboração dos filmes biodegradáveis utilizou-se a técnica casting descrita por 
Vicentini (2003). As diferentes soluções filmogênicas foram preparadas com base em $2 \mathrm{~g}$ de fécula para $100 \mathrm{~mL}$ de água destilada, misturadas em soluções plastificantes que variaram de acordo com o delineamento experimental (Tabela 1), sendo aquecidas até a temperatura e o tempo de gelatinização da fécula previamente estabelecidos no RVA. Após a gelatinização, a solução foi aplicada sobre placas de Petri de polietileno de $8 \mathrm{~cm}$ de diâmetro e desidratadas em estufa a $30^{\circ} \mathrm{C}$ até massa constante. Posteriormente, as placas foram armazenadas em dessecador ambientado em umidade relativa de $54 \%$ (solução saturada de $\mathrm{NaCl}$ ) até a retirada dos filmes.

TABELA 1 - VARIÁVEIS INDEPENDENTES E SEUS NÍVEIS A SEREM ESTUDADOS

\begin{tabular}{cccccc}
\hline \multirow{2}{*}{ Fator } & \multicolumn{5}{c}{ Níveis dos fatores } \\
\cline { 2 - 6 } & $-\alpha(1,414)$ & -1 & 0 & +1 & $+\alpha(1,414)$ \\
\hline Glicerol (\%) & 10 & 12,93 & 20 & 27,07 & 30 \\
Massa (g) & 19,17 & 20 & 22 & 24 & 24,83 \\
\hline
\end{tabular}

Analisou-se a aparência dos filmes em microscópio óptico Leica, sob lentes oculares objetivas de $100 \mathrm{X}$, com auxílio do óleo de imersão tipo A. Para isto, aproximadamente $2 \mathrm{~mm}^{2}$ do filme foi recortado e colocado em lâmina histológica umedecida com água destilada e depois coberto com lamínula. As imagens foram analisadas pelo software LAS EZ (LEICA..., 2010).

A espessura foi medida em dez pontos distintos (sendo um deles o central) em micrômetro manual externo (Digimess, São Paulo, SP, Brasil), com precisão de 0,001 mm.

Verificou-se a solubilidade usando amostras com $2 \mathrm{~cm}$ de diâmetro e umidade conhecida, pesadas e mergulhadas em $50 \mathrm{~mL}$ de água destilada. O sistema foi agitado lentamente em mesa agitadora orbital (Tecnal, TE-420, Piracicaba, Brasil) por $24 \mathrm{~h}$, a $25^{\circ} \mathrm{C}$. Após esse período, as amostras foram retiradas da água e secas (a $105^{\circ} \mathrm{C}$ por $24 \mathrm{~h}$ ) em estufa para determinar o peso do material não solubilizado. A solubilidade foi expressa pela porcentagem do material:

$$
\text { Massa }(\%)=\frac{P I-P F}{P I} \times 100
$$

Em que:

$\mathrm{PI}=$ massa inicial do material seco;

$\mathrm{PF}=$ massa do material seco não solubilizado.

Determinou-se a permeabilidade gravimetricamente, segundo teste da ASTM modificado por Gontard, Guilbert e Cuq (1993). Os biofilmes elaborados foram colocados em célula contendo sílica gel (UR $=0 \% ; 0 \mathrm{mmHg}$ pressão de vapor), constituindo uma membrana. A célula foi colocada dentro de dessecador contendo água destilada (UR $=100 \% ; 32,23 \mathrm{mmHg}$ pressão de vapor), em sala climatizada a $22^{\circ} \mathrm{C}$ e posteriormente, pesada em balança analítica (Bioprecisa, FA2104N, São Paulo, SP, Brasil) a cada 24h, totalizando 144h (seis dias consecutivos). A permeabilidade foi calculada como: 


$$
P v a=\frac{G V}{A T\left(p_{1}-p_{2}\right)}
$$

Em que:

Pva = permeabilidade ao vapor d'água $\left(\mathrm{g} \mathrm{mm} \mathrm{m}^{-2} \mathrm{~d}^{-1} \mathrm{mmHg}^{-1}\right)$;

$\mathrm{G}=$ massa ganha pela célula durante $24 \mathrm{~h}(\mathrm{~g})$;

$V=$ espessura média do filme $(\mathrm{mm})$;

$A=$ superfície de permeação do filme $\left(\mathrm{m}^{2}\right)$;

$\mathrm{T}=$ tempo $(\mathrm{d})$;

$p_{1}-p_{2}=$ gradiente de pressão de vapor entre as superfícies do filme $(32,23 \mathrm{mmHg})$.

Para estudar o efeito da porcentagem de glicerol (GLI) na solução filmogênica (SF) e da massa de SF sobre a solubilidade e permeabilidade dos filmes biodegradáveis adotou-se delineamento central composto, tipo estrela, com cinco repetições no ponto central e quatro axiais. As variáveis foram estabelecidas com três níveis codificados $-1,0,+1$ de acordo com Box, Hunter e Hunter (1978). O delineamento apresentou quatro níveis de variáveis axiais codificados como $-\alpha \mathrm{e}$ $+\alpha$. O valor de $\alpha$ é função do número de variáveis independentes, sendo definido como:

$$
\alpha=\left(2^{k}\right)^{1 / 4}=\left(2^{2}\right)^{1 / 4}=1,414
$$

O delineamento estatístico exigiu número mínimo de tratamentos experimentais. Nesse experimento foram usados 11 tratamentos (com uma repetição), sendo quatro fatoriais (combinações dos níveis -1 e +1 ), quatro axiais (uma variável no nível $\pm \alpha$ e outra no nível 0 ) e cinco centrais, servindo como estimativa do erro experimental para determinar a precisão do modelo polinomial (COCHRAN e COX, 1964).

$\mathrm{Na}$ Tabela 1 apresentam-se os valores codificados e reais do delineamento experimental em estrela para duas variáveis independentes e cinco níveis de variação. As respostas $(Y)$ ou variáveis dependentes estudadas foram: solubilidade e permeabilidade.

Fazendo uso da análise de variância (ANOVA) ao nível de 5\% de probabilidade, equação de segunda ordem foi aplicada para estabelecer modelo matemático preditivo das variáveis dependentes (KHURI e CORNELL, 1987):

$$
Y=b_{0}+\sum_{i=1}^{k} b_{i} x_{i}+\sum_{i=1}^{k} b_{i i} x_{i}^{2}+\sum_{i<j} b_{i j} x_{i} x_{j}+\varepsilon
$$

Em que:

$Y=$ função resposta genérica;

$\mathrm{x}=$ variável estudada,

$b=$ os coeficientes estimados pelos métodos dos mínimos quadrados, sendo sua significância avaliada pelo valor da probabilidade ( $p$ ), adotando-se valor de $p \leq 0,05$ para todos os ensaios; e $\varepsilon=$ erro experimental.

A adequação do modelo polinomial foi avaliada comparando-se a proporção da variação explicada, isto é, pela análise do coeficiente de determinação $\mathrm{R}^{2}$ e pelo método de seleção para frente (forward selection) até que o valor das somas dos quadrados do erro (SQE) não variasse ou até completar os coeficientes do modelo proposto.

Uma vez obtido o modelo polinomial ajustado às respostas, sua otimização foi efetuada pela técnica proposta para variáveis dependentes (DERRINGER e SUICH, 1980), que se baseia na definição de uma função de desejabilidade (D) restrita ao intervalo de 0 a 1. Quanto maior o valor 
de $D$, mais conveniente será a resposta do sistema, sendo que o valor máximo de $D$ é a solução otimizada do sistema.

Os gráficos de superfície de resposta foram desenhados por meio do modelo matemático proposto nos níveis reais das variáveis, mantendo-se a resposta em função do eixo Z, com os eixos $\mathrm{X}$ e $\mathrm{Y}$ representando as variáveis independentes ao mesmo tempo em que mantém as demais variáveis constantes no ponto central.

Os dados experimentais foram descritos por meio de médias e desvios-padrão, sendo processados e analisados com o auxílio do programa Statistica 8.0 (STATSOFT, 2007).

\section{RESULTADOS E DISCUSSÃO}

\subsection{CARACTERIZAÇÃO DOS RIZOMAS FILHO}

Os rizomas filhos do mangarito (Figura 1) apresentaram forma irregular com diferentes dimensões e massa. A polpa branca não se oxida em contato com o ar, constituindo vantagem para sua extração e purificação sem o uso de agentes antioxidantes. No entanto, na superfície observase película fina de cor marrom que requer abundante água para a sua retirada e que, assim mesmo, permanece durante o processo de extração, exigindo peneiragens sucessivas com peneiras finas e tempo prolongado (18 a $24 \mathrm{~h}$ ) para sua separação.

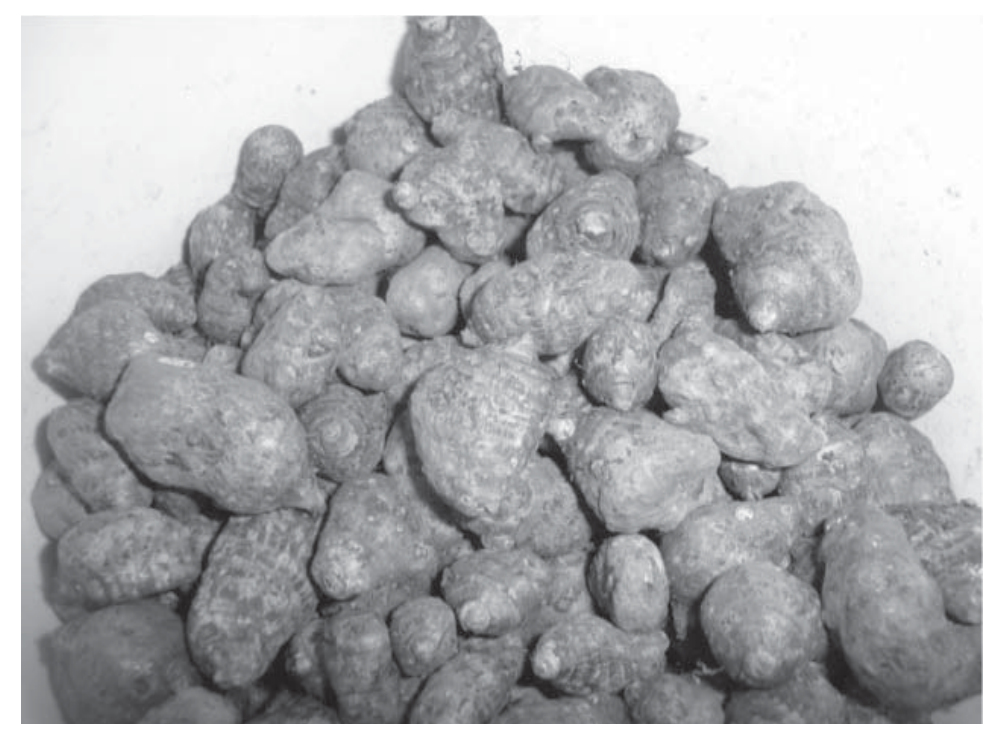

\section{FIGURA 1 - RIZOMAS FILHOS DO MANGARITO (Xanthosoma mafaffa Schott) COLETADOS NO MUNICÍPIO DE UBERLÂNDIA (MG)}

As Figuras $2 \mathrm{a}$ e $2 \mathrm{~b}$ mostram a distribuição dos diâmetros menor e maior dos rizomas filho de mangarito, que ficaram em torno de 20 a $26 \mathrm{~mm}$ e de 12 a $18 \mathrm{~mm}$, com média aproximada de 23 e $15 \mathrm{~mm}$, respectivamente. A massa média desses rizomas ficou entre 2 e $5 \mathrm{~g}$ (Figura 2c), sendo a média de aproximadamente $3,5 \mathrm{~g}$. Suas dimensões são vantajosas para a moagem em moinho de facas, sem que os rizomas sejam previamente fatiados para o processo de extração e purificação da fécula. Monteiro e Peressin (1997) estudaram rizomas filhos, provenientes de três municípios distintos do Estado de São Paulo, e chegaram a resultado semelhante (cerca de 1,5 a $4,5 \mathrm{~g})$.

A composição química dos rizomas filho de mangarito (Tabela 2) corresponde a produto amiláceo altamente energético, constituído principalmente de fécula (91,35 g/100 g bs). 


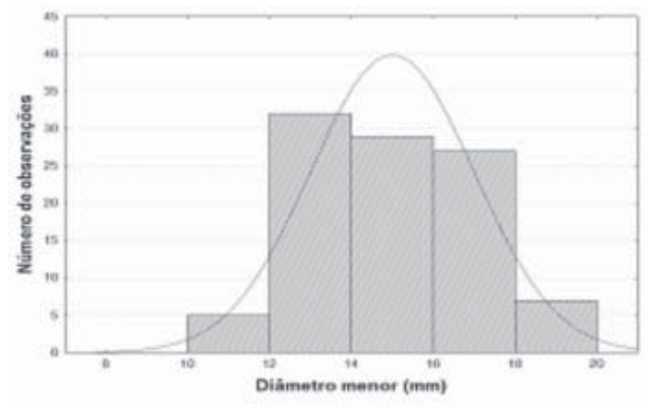

(a)

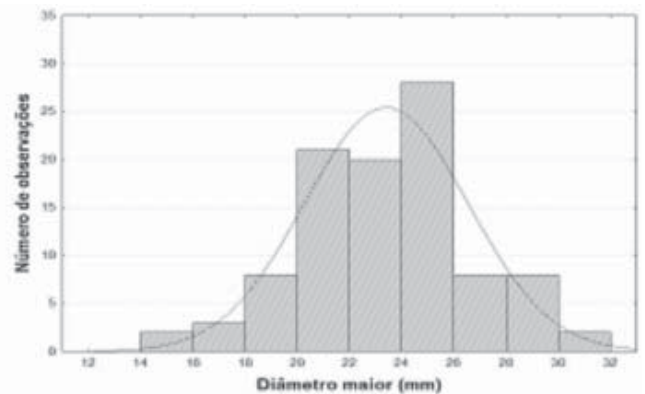

(b)

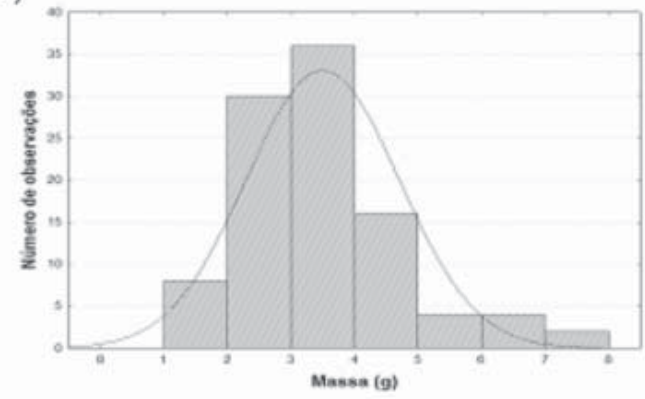

(c)

FIGURA 2 - FREQUÊNCIAS DE DISTRIBUIÇÃO DE: (a) DIÂMETRO MENOR, (b) DIÂMETRO MAIOR e (c) MASSA DOS RIZOMAS FILHOS DO MANGARITO (Xanthosoma mafaffa Schott)

Os resultados obtidos (Tabela 2) são semelhantes aos relatados por Cereda (2001) para o mesmo rizoma, entretanto sem informar se é filho ou mãe. A diferença marcante no teor de cinzas pode estar associada à presença da casca ou diferenças entre as regiões de plantio e suas respectivas características (oferta de água e de nutrientes, do espaçamento e da época do plantio). Costa et al. (2008) verificaram que o valor nutricional desse rizoma é comparável ao da batata.

\section{TABELA 2 - COMPOSIÇÃO CENTESIMAL DOS RIZOMAS FILHOS DO MANGARITO (Xanthosoma mafaffa Schott), EM BASE ÚMIDA E SECA}

Componente

Média \pm Desvio Padrão

\begin{tabular}{lcc}
\cline { 2 - 3 } & Base Úmida & Base Seca \\
\hline Umidade $(\mathrm{g} / 100 \mathrm{~g})$ & $73,51 \pm 0,44$ & - \\
Cinzas $(\mathrm{g} / 100 \mathrm{~g})$ & $1,50 \pm 0,03$ & $5,54 \pm 0,05$ \\
Lipídios $(\mathrm{g} / 100 \mathrm{~g})$ & $0,12 \pm 0,02$ & $1,43 \pm 0,36$ \\
Proteínas $(\mathrm{g} / 100 \mathrm{~g})$ & $2,15 \pm 0,65$ & $3,20 \pm 0,05$ \\
Fibra Bruta $(\mathrm{g} / 100 \mathrm{~g})$ & $2,39 \pm 0,37$ & $4,29 \pm 0,07$ \\
Açucares Redutores $(\mathrm{g} / 100 \mathrm{~g})$ & $0,19 \pm 0,09$ & $0,05 \pm 0,02$ \\
Açucares não redutores $(\mathrm{g} / 100 \mathrm{~g})$ & $0,12 \pm 0,09$ & $0,01 \pm 0,01$ \\
Açucares Totais $(\mathrm{g} / 100 \mathrm{~g})$ & $0,31 \pm 0,16$ & $0,06 \pm 0,02$ \\
Carboidratos $(\mathrm{g} / 100 \mathrm{~g})$ & $22,72 \pm 0,87$ & $96,23 \pm 0,33$ \\
Amido $(\mathrm{g} / 100 \mathrm{~g})$ & $21,11 \pm 0,87$ & $91,35 \pm 2,48$ \\
Valor Energético $(\mathrm{kcal} / 100 \mathrm{~g})$ & $100,56 \pm 1,92$ & $369,00 \pm 2,28$ \\
\hline
\end{tabular}




\subsection{CARACTERIZAÇÃO DA FÉCULA DOS RIZOMAS FILHO}

A extração e purificação da fécula dos rizomas foram eficientes, uma vez que os grânulos apresentaram baixos teores de outras frações em sua composição química (Tabela 3).

\section{TABELA 3 - COMPOSIÇÃO CENTESIMAL DA FÉCULA ISOLADA DOS RIZOMAS FILHOS DO MANGARITO (Xanthosoma mafaffa Schott) EM BASE ÚMIDA E SECA}
Componente
Média \pm Desvio Padrão

\begin{tabular}{lrr}
\cline { 2 - 3 } & Base Úmida & Base Seca \\
\hline Umidade $(\mathrm{g} / 100 \mathrm{~g})$ & $7,40 \pm 0,37$ & $8,01 \pm 0,02$ \\
Cinzas $(\mathrm{g} / 100 \mathrm{~g})$ & $0,12 \pm 0,03$ & $0,13 \pm 0,03$ \\
Lipídios $(\mathrm{g} / 100 \mathrm{~g})$ & $0,06 \pm 0,01$ & $0,07 \pm 0,01$ \\
Proteínas $(\mathrm{g} / 100 \mathrm{~g})$ & $0,61 \pm 0,17$ & $0,66 \pm 0,18$ \\
Fibra Bruta $(\mathrm{g} / 100 \mathrm{~g})$ & $0,37 \pm 0,05$ & $0,40 \pm 0,05$ \\
Açucares redutores $(\mathrm{g} / 100 \mathrm{~g})$ & $0,25 \pm 0,20$ & $0,27 \pm 0,22$ \\
Açucares não redutores $(\mathrm{g} / 100 \mathrm{~g})$ & $0,37 \pm 0,18$ & $0,41 \pm 0,19$ \\
Açucares Totais $(\mathrm{g} / 100 \mathrm{~g})$ & $0,64 \pm 0,38$ & $0,69 \pm 0,42$ \\
Carboidratos $(\mathrm{g} / 100 \mathrm{~g})$ & $91,81 \pm 0,33$ & $99,15 \pm 0,21$ \\
Amido $(\mathrm{g} / 100 \mathrm{~g})$ & $88,14 \pm 1,41$ & $95,19 \pm 1,90$ \\
\hline
\end{tabular}

Os grânulos da fécula, visualizados na Figura 3, apresentaram forma arredondada, circular e alguns ainda sendo formados. Verifica-se a presença do hilo e poucos grânulos danificados, o que pode ser decorrente do processo de moagem. A mesma morfologia foi observada por Leonel (2007) que estudou o amido da taioba, cultura pertencente à mesma família e gênero do mangarito.

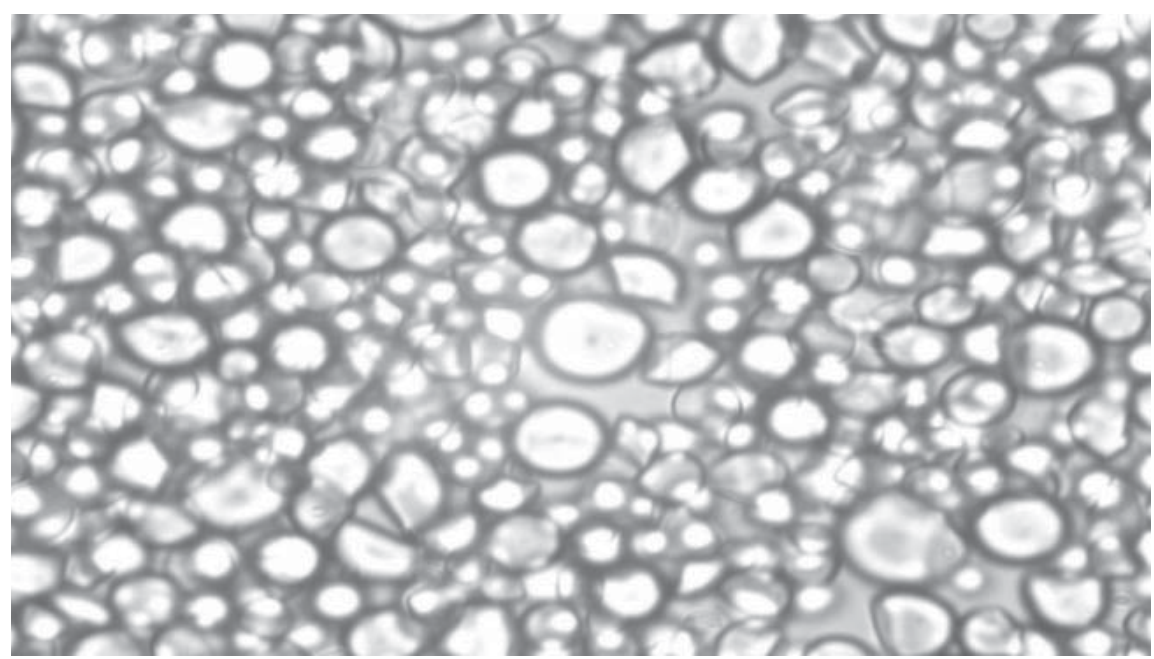

\section{FIGURA 3 - MICROFOTOGRAFIA DE GRÂNULOS DA FÉCULA ISOLADA DE RIZOMAS FILHOS DO MANGARITO (Xanthosoma mafaffa Schott)}

O tamanho dos grânulos da fécula, entre 5,36 e 22,13 $\mu \mathrm{m}$, com maior concentração entre 10 e $15 \mu \mathrm{m}$, alcançaram média de 12,5 $\mu \mathrm{m}$ (Figura 4). Esses dados se assemelham aos da taioba (LEONEL, 2007) que apresenta diâmetro entre 5 a 25 m, com maior concentração de grânulos com 10 a $15 \mu \mathrm{m}$. De acordo com Vieira (2004), o tamanho dos grânulos e sua distribuição estão entre os 
fatores que influenciam as propriedades funcionais dos amidos. Grânulos pequenos $(2,0 \mu \mathrm{m})$ podem ser usados como substitutos de gordura devido ao tamanho ser semelhante ao dos lipídios. $O$ tamanho dos grânulos também se torna importante na produção de filmes plásticos biodegradáveis e de papéis para fax (LEONEL, 2007). Além disso, constitui importante parâmetro para se definir etapas do processo de extração desse polissacarídeo.

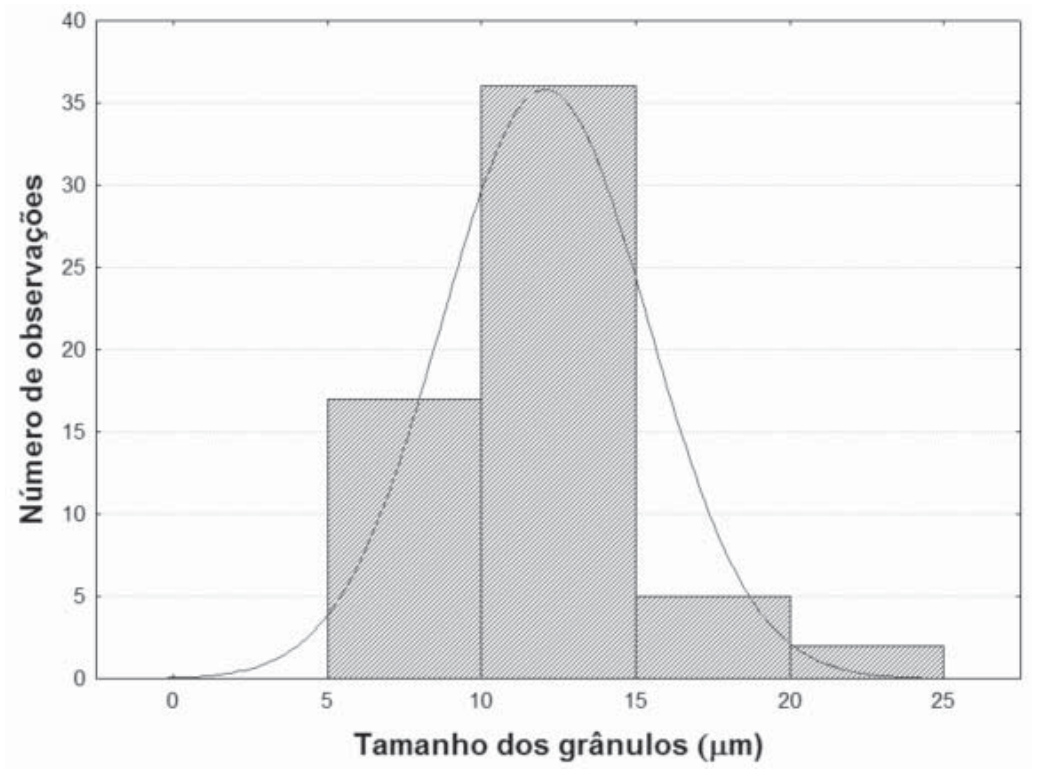

\section{FIGURA 4 - FREQUÊNCIA DO TAMANHO DOS GRÂNULOS DA FÉCULA ISOLADA DE} RIZOMAS FILHOS DO MANGARITO (Xanthosoma mafaffa Schott)

A Figura 5 mostra o perfil de RVA da fécula de rizomas filhos do mangarito.

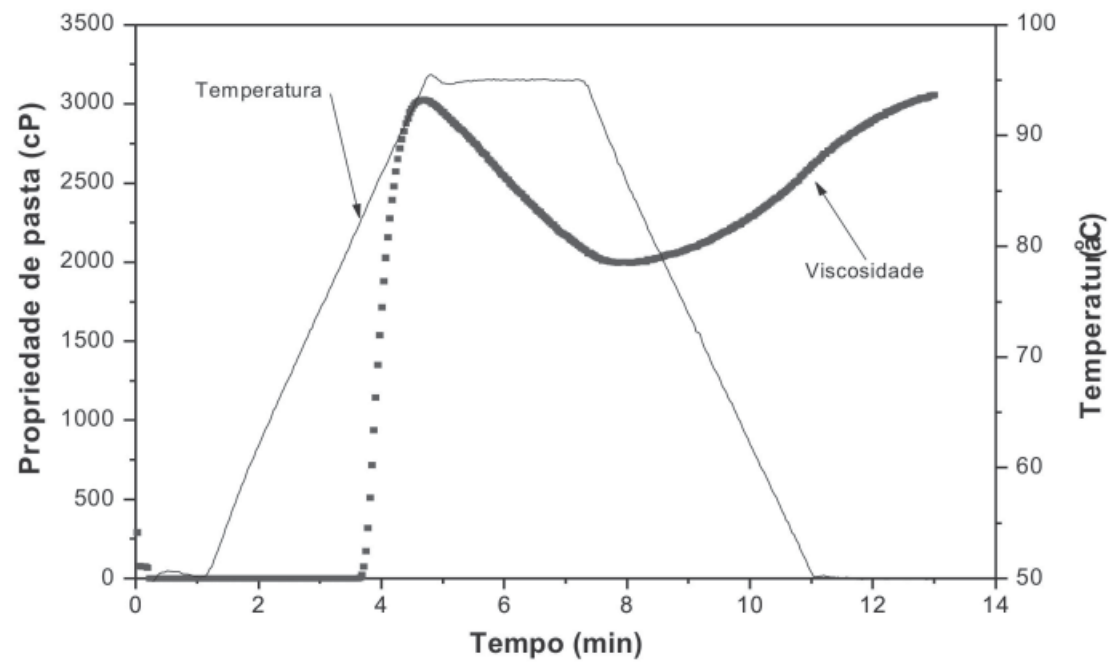

\section{FIGURA 5 - PERFIL DE VISCOSIDADE DE PASTA DA FÉCULA ISOLADA DOS RIZOMAS FILHOS DO MANGARITO (Xanthosoma mafaffa Schott)}

Nos primeiros 3,6 min (tempo de pasta), os grânulos de fécula não sofreram modificação e a viscosidade mostrou-se muito baixa $(0,5 \mathrm{cP})$. A alta temperatura de pasta $\left(82,15^{\circ} \mathrm{C}\right)$ indicou fécula com alta resistência à expansão. Após o início da formação de pasta, os grânulos começaram a intumescer, aumentando a viscosidade até $3031,50 \mathrm{cP}$ (viscosidade de pico no ciclo de aquecimento) 
em $4,7 \mathrm{~min}$, a aproximadamente $95^{\circ} \mathrm{C}$. Durante o período de aquecimento, o perfil de viscosidade apresentou formato pouco arredondado com aumento mais abrupto da viscosidade em função da elevação da temperatura. Isso indica homogeneidade das forças de ligações que mantêm os grânulos e certa resistência (coesão entre elas), o que torna seu gel relativamente resistente ao cozimento e à ação mecânica, provocando queda de 1039,50 cP na viscosidade (quebra) em 4,8 min. Durante o período de resfriamento, o aumento da viscosidade foi de 1063,50 cP (tendência à retrogradação), atingindo viscosidade final de 3055,50 cP.

De acordo com Krieger et al. (1997), as propriedades térmicas durante o processo de gelatinização do amido são muito importantes para a determinação de sua funcionalidade e uso pela indústria. As propriedades térmicas da fécula dos rizomas filhos do mangarito estão apresentadas na Tabela 4. Relacionando as temperaturas iniciais de gelatinização $\left(T_{0}\right)$, obtidas no DSC com as temperaturas de pasta do RVA, observa-se que a temperatura inicial de formação de pasta da fécula do mangarito apresentou valor menor em relação à temperatura de formação de pasta $\left(82,15^{\circ} \mathrm{C}\right) . \mathrm{O}$ mesmo foi observado por Peroni (2003) para fécula de mandioca, biri e outras espécies amiláceas que apresentam valores de empastamento maiores do que os obtidos pelo DSC. De acordo com Pérez, Breene e Bahnassey (1998), a temperatura de pasta obtida pelo RVA apresenta-se maior devido à menor sensibilidade em detectar os primeiros acréscimos na viscosidade de pasta dos amidos, diferentemente da temperatura inicial de gelificação, detectada quando os primeiros grânulos começam a se desorganizar. Assim, os valores do DSC são mais precisos, enquanto os do RVA indicam a faixa de temperatura.

Segundo Krueger et al. (1987) e Yoo e Jane (2002), uma única endoterma apresentada para todos os amidos significa que não há amilose complexada com lipídios, pois se existentes poderiam fundir proporcionando endoterma na faixa de temperatura de $91-100^{\circ} \mathrm{C}$. Isso era de se esperar, pois os amidos de raízes, rizomas e tubérculos contém quantidades muito baixas de lipídios.

\section{TABELA 4 - PROPRIEDADES DE GELATINIZAÇÃO DA FÉCULA ISOLADA DOS RIZOMAS FILHOS DO MANGARITO (Xanthosoma mafaffa Schott)}

\begin{tabular}{cccc}
\hline \multicolumn{4}{c}{ Gelificação } \\
\hline $\mathrm{T}_{0}\left({ }^{\circ} \mathrm{C}\right)$ & $\mathrm{T}_{\mathrm{p}}\left({ }^{\circ} \mathrm{C}\right)$ & $\mathrm{T}_{\mathrm{c}}\left({ }^{\circ} \mathrm{C}\right)$ & $\Delta \mathrm{H}(\mathrm{J} / \mathrm{g})$ \\
\hline 76,2 & 78,42 & 81,00 & 0,16 \\
\hline
\end{tabular}

To = temperatura inicial, $\mathrm{Tp}=$ temperatura de pico, $\mathrm{Tc}=$ temperatura de conclusão e $\Delta \mathrm{H}=$ variação de entalpia

O valor da endoterma da fécula, de 0,16 J.g-1, pode indicar fraca associação da amilopectina, resultando em menor força necessária para provocar o rompimento da estrutura dos grânulos e, consequentemente, ocorrer a gelatinização. De acordo com Noda et al., citados por Singh et al. (2004), as temperaturas inicial, de pico e final são influenciadas pela estrutura molecular da região cristalina, que corresponde à distribuição das cadeias curtas de amilopectina. Para Fernandes (2009), a variação de entalpia do gel pode ser correlacionada com a cristalinidade da amilopectina e com a força com que as duplas hélices formadas por suas cadeias estão associadas com o grânulo do amido. Assim, quanto maior esse valor maior será a força necessária para o rompimento da estrutura dos grânulos, resultando na gelatinização da fécula.

\subsection{CARACTERIZAÇÃO DOS FILMES BIODEGRADÁVEIS}

Mostra-se na Figura 6, exemplo de filme biodegradável elaborado com a fécula dos rizomas filho de mangarito, água e glicerol. A variação na concentração de glicerol e da espessura não influenciou seu aspecto visual, geralmente transparente, incolor e flexível. No entanto, alguns se apresentaram mais quebradiços e de difícil manuseio. 


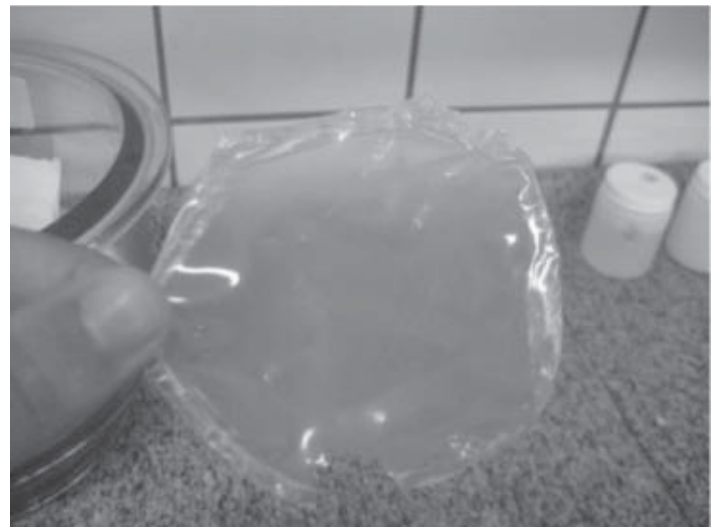

\section{FIGURA 6 - FOTO DE FILME BIODEGRADÁVEL À BASE DE FÉCULA DE RIZOMAS FILHO DE MANGARITO, ÁGUA E GLICEROL}

A Figura 7 mostra as condições nas quais as soluções filmogênicas foram submetidas: disponibilidade de água, tempo e temperatura de gelatinização e temperatura utilizada para sua secagem $\left(30^{\circ} \mathrm{C}\right)$. Os filmes apresentam superfícies homogêneas, atingindo a uniformidade desejável da gelatinização dos grânulos da fécula, assim como plasticidade e transparência. Não foram observados os chamados fantasmas de amido (grânulos de amido parcialmente gelatinizados) como reportados por Moura (2008).
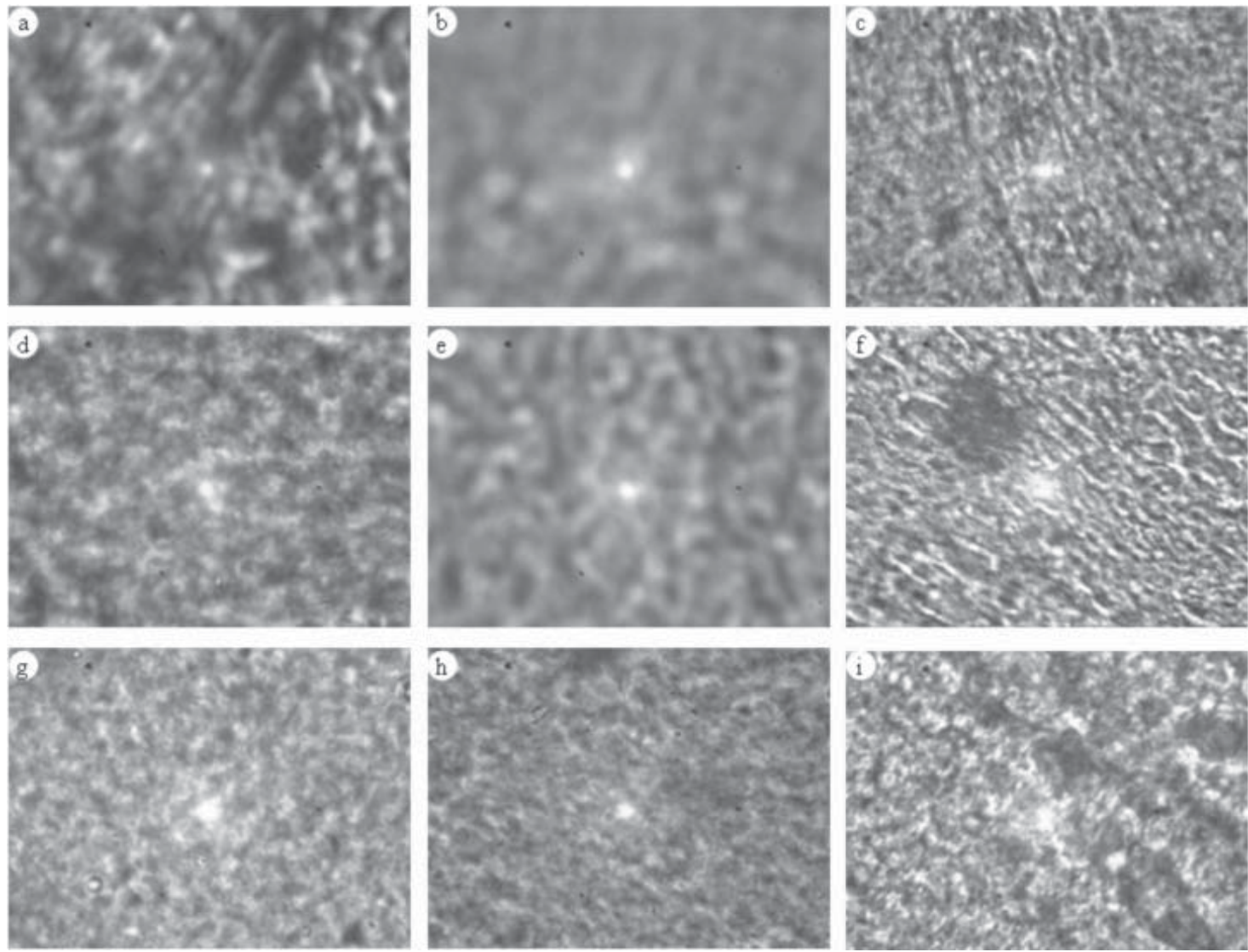

\section{FIGURA 7 - MICROFOTOGRAFIAS DE FILME BIODEGRADÁVEL ELABORADO À PARTIR DE FÉCULA DO MANGARITO (Xanthosoma mafaffa Schott) E GLICEROL}

a) Tratamento 1; b) Tratamento 2; c) Tratamento 3; d) Tratamento 4; e) Tratamento 5; f) Tratamento 6; g) Tratamento 7; h) Tratamento 8; i) Tratamento 9. 
Os filmes foram caracterizados quanto à espessura, solubilidade em água e permeabilidade ao vapor de água (Tabela 5).

\section{TABELA 5 - RESULTADOS EXPERIMENTAIS DAS PROPRIEDADES DOS FILMES BIODEGRADÁVEIS ELABORADOS À BASE DE FÉCULA DE MANGARITO, ÁGUA E GLICEROL}

\begin{tabular}{cccccc} 
Tratamentos & Glicerol $(\%)$ & $\begin{array}{c}\text { Massa* } \\
(\mathrm{g})\end{array}$ & Espessura $(\mathrm{mm})$ & Solubilidade $(\%)$ & $\begin{array}{c}\text { Pva }\left(\times 10^{-5}\right) \\
{\left[\mathrm{g}(\mathrm{m} \mathrm{s} \mathrm{Pa})^{-1}\right]}\end{array}$ \\
\hline T1 & 12,93 & 20 & $0,044 \pm 0,004$ & $10,94 \pm 0,05$ & $7,96 \pm 1,06$ \\
T2 & 12,93 & 24 & $0,056 \pm 0,006$ & $32,905 \pm 1,24$ & $7,97 \pm 0,18$ \\
T3 & 27,07 & 20 & $0,064 \pm 0,004$ & $18,67 \pm 0,50$ & $10,74 \pm 1,02$ \\
T4 & 27,07 & 24 & $0,078 \pm 0,004$ & $36,22 \pm 0,53$ & $12,75 \pm 0,34$ \\
T5 & 10 & 22 & $0,035 \pm 0,004$ & $9,24 \pm 0,44$ & $5,55 \pm 0,61$ \\
T6 & 30 & 22 & $0,081 \pm 0,001$ & $27,66 \pm 0,93$ & $11,66 \pm 0,99$ \\
T7 & 20 & 19,17 & $0,066 \pm 0,003$ & $16,67 \pm 0,45$ & $8,30 \pm 0,68$ \\
T8 & 20 & 24,82 & $0,070 \pm 0,003$ & $35,00 \pm 1,39$ & $9,36 \pm 0,47$ \\
T9 & 20 & 22 & $0,058 \pm 0,006$ & $16,99 \pm 1,31$ & $9,03 \pm 1,33$ \\
T10 & 20 & 22 & $0,056 \pm 0,000$ & $16,39 \pm 0,73$ & $8,97 \pm 1,33$ \\
T11 & 20 & 22 & $0,061 \pm 0,003$ & $15,99 \pm 0,10$ & $8,80 \pm 0,77$ \\
\hline
\end{tabular}

* Massa de solução filmogênica.

Definiu-se a espessura dos filmes como a distância perpendicular entre duas superfícies principais do material (HENRIQUE, CEREDA e SARMENTO, 2008). Seu controle (apesar de difícil nos processos de produção do tipo casting) é de extrema importância, pois influencia diretamente propriedades como, por exemplo, a solubilidade e a permeabilidade ao vapor de água (MALI, GROSSMANN e YAMASHITA, 2010; SOBRAL, 2000; SABATO, 2000).

A espessura dos filmes de fécula de mangarito variou significativamente (Tabela 6) em função da concentração de glicerol e da quantidade de solução filmogênica $(p<0,01)$. Independente da interação, o efeito dos fatores foi positivo indicando que quanto maior a adição de glicerol na formulação e mais elevada quantidade de massa da SF, maior será a espessura do filme elaborado.

Aplicando o teste t ao nível de 1 e $5 \%$ de probabilidade, selecionaram-se os coeficientes lineares do modelo polinomial de segundo grau (Eq. 4) ajustado aos dados experimentais de espessura dos filmes (Tabela 6 ). $O R^{2}$ mostrou que mais de $92 \%$ da variação foi devido à regressão, portanto o modelo é preditivo e foi descrito como:

$$
\text { Espessura }(\mathrm{mm})=-0,0208+0,0019 \mathrm{GLI}+0,002 \mathrm{SF}
$$

O gráfico desenhado pela Equação 5 está na Figura 8a. O aumento do glicerol e da quantidade de solução filmogênica gerou filmes com espessura maior, podendo-se alcançar o máximo de $0,086 \mathrm{~mm}$ para $30 \%$ de GLI e $25 \mathrm{~g}$ de SF, e o mínimo de $0,036 \mathrm{~mm}$ para $10 \%$ de GLI e $19 \mathrm{~g}$ de SF. 


\section{TABELA 6 - TESTE F, COEFICIENTES DO MODELO POLINOMIAL DE SEGUNDO GRAU APLICADO (Coef.), COEFICIENTE DE DETERMINAÇÃO (R²) E RESPECTIVAS SIGNIFICÂNCIAS ESTATÍSTICAS}

\begin{tabular}{|c|c|c|c|c|c|c|}
\hline \multirow{2}{*}{ Fator } & \multicolumn{2}{|c|}{ Espessura } & \multicolumn{2}{|c|}{ Solubilidade } & \multicolumn{2}{|c|}{ Permeabilidade ao vapo } \\
\hline & Teste F & Coef. & Teste F & Coef. & Teste F & Coef. \\
\hline Interc. & - & $-0,0208^{\text {ns }}$ & - & $536,58^{* *}$ & - & $43,11^{*}$ \\
\hline GLI & $227,39^{* *}$ & $0,0019^{* *}$ & $678,01^{* *}$ & $1,06^{\mathrm{ns}}$ & $2336,60^{* *}$ & $-0,59^{*}$ \\
\hline $\mathrm{GLI}^{2}$ & $0,62^{\text {ns }}$ & - & $59,25^{*}$ & $0,03^{*}$ & $6,06^{\mathrm{ns}}$ & $0,00^{\text {ns }}$ \\
\hline SF & $19,96^{* *}$ & $0,0020^{* *}$ & $2108,42^{* *}$ & $-52,94^{* *}$ & $109,54^{* *}$ & $-3,05^{*}$ \\
\hline $\mathrm{SF}^{2}$ & $16,03^{*}$ & - & $630,79^{* *}$ & $1,33^{* *}$ & $21,96^{*}$ & $0,06^{*}$ \\
\hline GLI x SF & $0,16^{\text {ns }}$ & - & $19,07^{*}$ & $-0,08^{*}$ & $70,58^{* *}$ & $0,04^{*}$ \\
\hline F. de aj. & $6,91^{\text {ns }}$ & - & $84,12^{*}$ & - & $65,80^{*}$ & - \\
\hline $\mathrm{R}^{2}$ & \multicolumn{2}{|c|}{0,922} & \multicolumn{2}{|c|}{0,931} & \multicolumn{2}{|c|}{0,927} \\
\hline
\end{tabular}

${ }^{*},{ }^{* *},{ }^{n s}=$ significativo, altamente significativo ao nível de $5 \%$ e $1 \%$ de probabilidade e não significativo, respectivamente.

O aumento da espessura com a adição de maior quantidade do plastificante também foi observado por Shimazu et al. (2007) em filmes elaborados com amido de mandioca e glicerol. Tais autores referiram que esse fenômeno ocorre pelo acréscimo de teor de sólidos na matriz polimérica formada após secagem das soluções filmogênicas. Isso pode ter ocorrido no presente estudo, pois o aumento da massa de SF eleva a quantidade de glicerol e de amido que com a gelatinização amplia o volume do filme biodegradável.

De acordo com a Tabela 5, os filmes de fécula de rizomas filho de mangarito e glicerol apresentaram solubilidade entre 9,24 e $36,22 \%$ e permeabilidade de $5,55 \times 10^{-5}$ e $12,75 \times 10^{-5} \mathrm{~g}$ $(\mathrm{m} \mathrm{s} \mathrm{Pa})^{-1}$. Esses resultados se devem principalmente à interação dos fatores glicerol versus massa de solução filmogênica (Tabela 6), isto é, a solubilidade depende do efeito sinérgico causado por esses fatores. As Equações 6 e 7 representam essas variações, respectivamente:

$$
\begin{aligned}
& \text { Solubilidade }(\%)=536,58+0,03 \mathrm{GLI}^{2}-52,94 \mathrm{SF}+1,33 \mathrm{SF}^{2}-0,08 \mathrm{GLI} \text { SF } \\
& \text { Pva }\left[\mathrm{g}(\mathrm{m} \mathrm{s} \mathrm{Pa})^{-1}\right]=43,11-0,59 \mathrm{GLI}-3,05 \mathrm{SF}+0,06 \mathrm{SF}^{2}+0,04 \mathrm{GLI} \mathrm{SF}
\end{aligned}
$$

Os gráficos da Figura 8b e 8c mostram as variações da solubilidade e do Pva dos filmes.

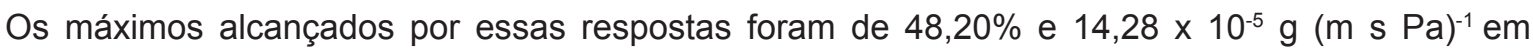
filmes elaborados com $30 \%$ de glicerol e $25 \mathrm{~g}$ de solução filmogênica. Já os mínimos atingidos foram de $8,75 \%$ de solubilidade em filmes com $10 \%$ de glicerol e $20 \mathrm{~g}$ de SF e $6,31 \mathrm{~g} \mathrm{(m} \mathrm{s} \mathrm{Pa})^{-1} \mathrm{de}$ permeabilidade em filmes elaborados com 10\% de glicerol e $22 \mathrm{~g}$ de SF. Segundo Cuq et al. (1997), a rede polimérica torna-se menos densa com a incorporação de glicerol e, consequentemente, mais permeável. Resultados semelhantes foram relatados por Gontard et al. (1993) em filmes de proteína e por Mali et al. (2004) em filmes de amido de inhame. Dias (2008), por sua vez, afirmou que a presença de plastificantes aumenta a taxa de difusão em polímeros, portanto, quanto maior a quantidade de plastificante maior a solubilidade e a permeabilidade ao vapor de água.

Quanto à otimização do processo de elaboração dos filmes deve ser considerado, de modo geral, que possam ser usados como embalagens protetoras de produtos contra alterações provocadas por fatores adversos à sua conservação (umidade, luz, reações bioquímicas, ataque microbiano, insetos, etc.). Portanto, devem apresentar boa propriedade de barreira ao vapor de água, isto é, baixa permeabilidade em grande faixa de umidade relativa (SARMENTO, 1999), baixa solubilidade em água para manter a integridade do produto (PEREZ-GAGO e KROCHTA, 2001) e espessura que permita a manutenção da integridade do filme durante o processo de manipulação, empacotamento e transporte (DAVANÇO, 2006). 


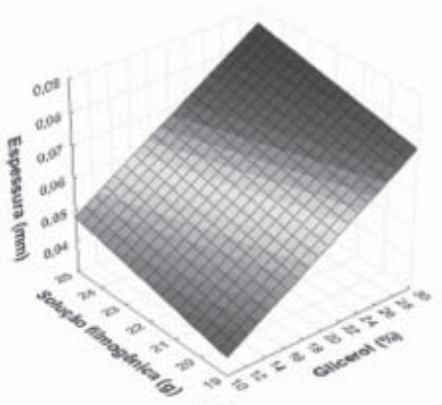

(a)

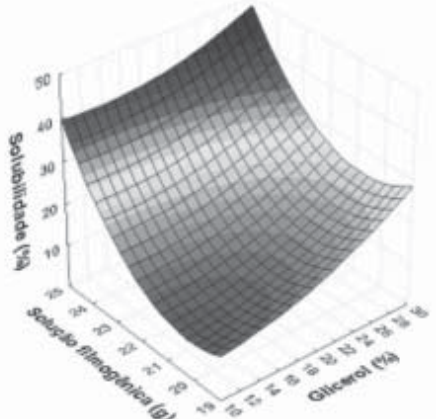

(b)

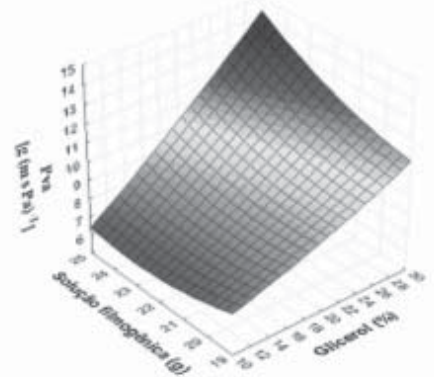

(c)

FIGURA 8 - INFLUÊNCIA DO GLICEROL E DA QUANTIDADE DE SOLUÇÃO FILMOGÊNICA NA ESPESSURA, SOLUBILIDADE E PERMEABILIDADE AO VAPOR DE ÁGUA (Pva) DE FILMES BIODEGRADÁVEIS À BASE DE FÉCULA DE RIZOMAS FILHO DE MANGARITO

No presente trabalho foram adotados critérios com base nas restrições anteriores para os valores mínimos, intermediários e máximos de cada resposta estudada para encontrar valores operacionais ótimos das variáveis independentes que satisfaçam simultaneamente todos os requisitos necessários às variáveis respostas (função desejabilidade), com valores baixos de permeabilidade e espessura e alta solubilidade. Esses critérios podem ser vistos na Tabela 7.

TABELA 7 - CONDIÇÕES DE DESEJABILIDADE (d) ADOTADOS AOS VALORES MÍNIMOS, INTERMEDIÁRIOS E MÁXIMOS DAS VARIÁVEIS RESPOSTA DURANTE A OTIMIZAÇÃO DA PRODUÇÃO DOS FILMES BIODEGRADÁVEIS À BASE DE FÉCULA DE RIZOMAS FILHO DE MANGARITO EM FUNÇÃO DA ADIÇÃO DO GLICEROL E DA QUANTIDADE DE MASSA DE SOLUÇÃO FILMOGÊNICA

\begin{tabular}{lcccc}
\hline \multirow{2}{*}{ Variável resposta } & & Mínimo & Médio & Máximo \\
& & & & \\
\hline \multirow{3}{*}{ Espessura } & Valor $(\mathrm{mm})$ & 0,035 & 0,058 & 0,081 \\
Solubilidade & $\mathrm{d}_{\mathrm{i}}$ & 1,0 & 0,5 & 0,0 \\
Permeabilidade & Valor $(\%)$ & 9,24 & 22,73 & 36,22 \\
& $\mathrm{~d}_{\mathrm{i}}$ & 0,0 & 0,5 & 1,0 \\
& Valor $\left[\mathrm{g}\left(\mathrm{m} \mathrm{sa}^{-1}\right]\right.$ & 5,55 & 9,15 & 12,75 \\
& $\mathrm{~d}_{\mathrm{i}}$ & 1,0 & 0,5 & 0,0 \\
\hline
\end{tabular}

Com base nos resultados da função desejabilidade (Figura 9) foi possível verificar que para se obter o máximo valor dessa função global (igual a 0,84 ) ter-se-á que operar os fatores 
GLI e SF em: $10,0 \%$ e $24,73 \mathrm{~g}$, respectivamente. O filme assim elaborado terá espessura de $0,035 \mathrm{~mm}$, solubilidade de $36,22 \%$ e permeabilidade de 5,55 [g ( $\left.\mathrm{m} \mathrm{s} \mathrm{Pa})^{-1}\right]$. Nessas condições, o filme elaborado com fécula de rizoma filho de mangarito e glicerol poderá ser aplicado em produtos que necessitem de hidratação prévia ao consumo, como cobertura de sementes agrícolas que exijam rápida absorção de água para germinar no campo, ou como carreadores de aditivos necessários ao seu crescimento (BATISTA, TANADA-PALMU e GROSSO, 2005).
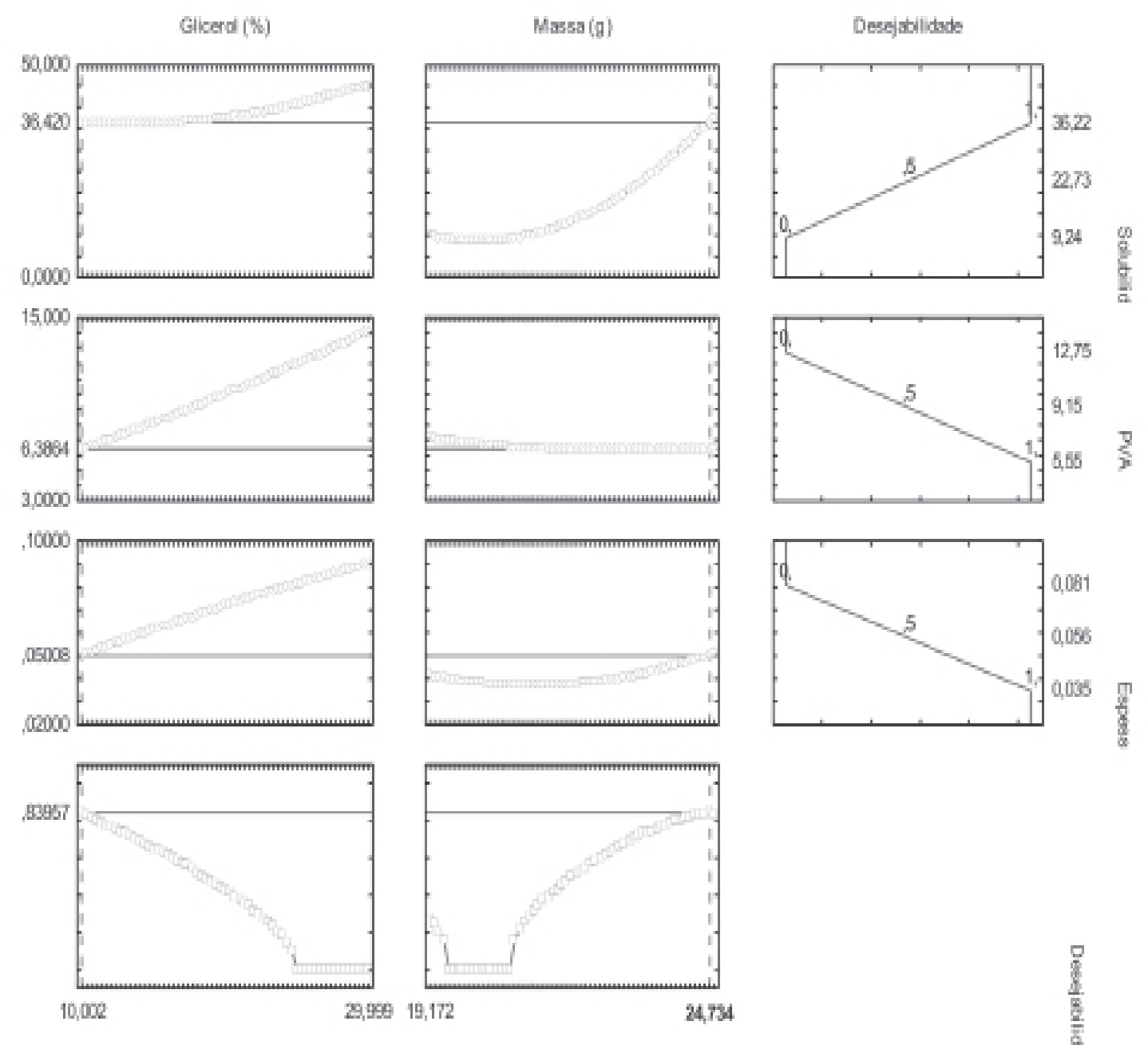

\section{FIGURA 9 - RESULTADOS DA FUNÇÃO DESEJABILIDADE DE FILMES BIODEGRADÁVEIS À BASE DE FÉCULA DE RIZOMAS FILHO DE MANGARITO E GLICEROL}

\section{CONCLUSÃO}

De acordo com as condições do presente trabalho conclui-se que os rizomas filhos do mangarito apresentam massa média de aproximadamente $3,5 \mathrm{~g}$ e diâmetros maiores e menores com média em torno de $23 \mathrm{~mm}$ e $15 \mathrm{~mm}$, respectivamente. São altamente energéticos e constituídos principalmente de fécula, não se oxidando em contato com o ar. Tais características os tornam adequados para uso como matéria-prima amilácea.

A fécula isolada dos rizomas, com formato arredondado, circular e tamanho variado (média de $12,5 \mu \mathrm{m}$ ) apresenta, também, elevada temperatura de empastamento, estabilidade frente ao calor sob agitação mecânica e grande tendência à retrogradação, podendo ser indicada para uso em indústrias de adesivos e alimentos.

Observando os dados estatísticos, nem todas as respostas foram afetadas pela interação 
dos fatores estudados. A interação entre a concentração de glicerol e a quantidade de solução filmogênica afetou a solubilidade em água e a permeabilidade dos filmes.

Ao considerar os fatores desejáveis de alta solubilidade e baixas permeabilidade ao vapor de água e espessura, os filmes produzidos com $10 \%$ de glicerol e $24,73 \mathrm{~g}$ de solução filmogênica atenderiam melhor tais características.

\section{ABSTRACT \\ CHARACTERIZATION OF THE COMELS AND STARCH FROM MANGARITO (Xanthosoma mafaffa Schott) AND DEVELOPMENT OF BIODEGRADABLE FILMS}

In this work, were determined the physical and chemical properties of the comels of mangarito starch and some properties of biodegradable films from starch and glycerol. Were determined the mass and the major and minor diameters and chemical composition of the comels. Were also determined the chemical composition and calorific value of the extracted starch, and its thermal and pasting properties. The morphology and size of their granules were analyzed. The films were prepared using the casting technique by varying the amount of glycerol and the mass of filmogenic solution according to a central composite factorial design. From the obtained films were studied the appearance, thickness, permeability and solubility. Was applied an analysis of variance for a second degree polynomial model and the desirability function for the optimization. The average weight of comels was $3.5 \mathrm{~g}$ with major and minor diameters of 23 and $15 \mathrm{~mm}$ respectively, being mainly constituted of granules with rounded $12.5 \mu \mathrm{m}$ in diameter. The starch paste presented good stability under heat and mechanical stirring and great tendency to retrogradation. Considering as desirable the factors low thickness and permeability and high solubility, films made with $10 \%$ glycerol and $24.73 \mathrm{~g}$ of filmogenic solution would comply better to these characteristics.

KEY-WORDS: Xanthosoma mafaffa Schott; PHYSICOCHEMICAL AND FUNCTIONAL PROPERTIES; STARCHES; BIODEGRADABLE FILMS.

\section{REFERÊNCIAS}

1 ALVES, M.M.; TOMÁS R. Embalagens biodegradáveis. In: CASTRO, A.G.; POUZADA, A.S. (Coord). Embalagens para a indústria alimentar. Lisboa: Instituto Piaget, 2003. p.371-388.

2 ASCHERI, D.P.R.; ANDRADE, C.T.; CARVALHO, C.W.P.; ASCHERI, J.L.R. Obtenção de farinhas mistas pré-gelatinizadas a partir de arroz e bagaço de jabuticaba: efeito das variáveis de extrusão nas propriedades de pasta. B. do CEPPA, Curitiba, v.24, n.1, p.115-144, jan/jun, 2006.

3 Association of Official Analytical Chemists (AOAC). Official methods of analysis of AOAC International. $17^{\text {th }}$ ed. Gaithersburg, 2000. v. 2

4 BATISTA, J.A.; TANADA-PALMU, P.S.; GROSSO, C.R.F. Efeito da adição de ácidos graxos em filmes à base de pectina. Ciência e Tecnologia de Alimentos, Campinas, v. 25, n.4, p.781-788, 2005.

5 BOBBIO, P.A.; BOBBIO, F.O. Química do processamento de alimentos. 3. ed. rev. São Paulo: Varela, 2003. 143 p.

6 BOX, G.E.P.; HUNTER, W.G.; HUNTER, J.S. Statistics for experimenters: an introduction to design, data analysis, and modo building. New York: Wiley and Sons, 1978. 653 p.

7 BRASIL. Ministério da Agricultura, Pecuária e Abstecimento. Instrução Normativa no 8, de 11 de março de 2009. Aprova o método oficial para determinação dos parâmetros para avaliação do teor total de água contida em cortes de aves. Diário Oficial [da] República Federativa do Brasil, Brasília, DF, 12 março. 2009, Seção 1, p. 2.

8 CARR, L.G.; PONCE, P.; PARRA, D.F.; LUGÃO, A.B.; BUCHLER, P.M. Influência da adição de caulim e CaCO3 nas propriedades mecânicas das espumas de amido. CONGRESSO BRASILEIRO DE ENGENHARIA E CIÊNCIAS DOS MATERIAIS, 17., 2006, Foz do Iguaçu. Resumo Expandido... Foz do Iguaçu: CBECiMat, 2006. p.8778-8786. Disponível em: < http://www.metallum.com.br/17cbecimat/resumos_area04.htm>. Acesso em: 02 abr. 2009.

9 CEREDA, M.P. Potencial das tuberosas americanas. SIMPÓSIO NACIONAL SOBRE CULTURAS DO INHAME E DO CARÁ, 2001, Venda Nova do Imigrante. Anais... . Venda Nova do Imigrante: Empresa de Pesquisa Agropecuária do Espírito Santo, 2001.

10 CEREDA, M.P.; DAIUTO, E.R.; VILPOUX, O. Metodologia de determinação de amido digestão ácida em microondas. ABAM, Paranavaí, v.2, n.8, p.1-29, 2004. 
11 COCHRAN, B.Y.; COX, G.M. Experimental designs. 2nd ed. New York: John Willey, 1964.

12 COSTA, C.A.da; RAMOS, S.J; ALVES, D.S.; FERNADES, L.A.; SAMPAIO, R.A.; MARTINS, E.R. Nutrição mineral do mangarito num Latossolo Vermelho Amarelo. Horticultura Brasileira, Brasília, v. 26, n. 1, p.102-106, 2008.

13 CUQ, B.; GONTARD, N.; CUQ, J.L.; GUILBERT, S. Selected functional properties of fish myofibrilar protein-based films as affected by hydrophilic plasticizers. Journal of Agricultural and Food Chemistry, Washington, v.45, n.3, p.622-626, 1997.

14 DAVANÇO, T. Desenvolvimento e caracterização de biofilmes à base de gelatina, triacetina, ácido esteárico ou ácido capróico e surfactantes. 2006. 130 f. Dissertação (Mestrado em Alimentos e Nutrição), Universidade Estadual de Campinas, Campinas, 2006

15 DERRINGER G. C.; SUICH, R. Simultaneous optimization of several responses variables. Journal of Quality Technology, v.12, n.4, p.214-219, 1980.

16 DIAS, A.B. Desenvolvimento e caracterização de filmes biodegradáveis obtidos de amido e de farinha de arroz. 2008. 116 p. (Mestrado em Engenharia de Alimentos), Universidade Federal de Santa Catarina , Florianópolis, 2008.

17 FAKIROV, S.; SARAC, Z.; ANBAR, T.; BOZ, B.; BAHAR, I.; EVSTATIEV, M.; APOSTOLOV, A.A.; MARK, J.E.; KLOCZKOWSKI, A. Mechanical properties and transition temperatures of crosslinked-oriented gelatin. Colloid and Polymer Science, Berlin, v.275, n.4, p.307-314, 1997.

18 FERNANDES, A.dos.S. Extração e caracterização do amido de fruta-do-lobo (Solanum lycocarpum St. Hill) e elaboração de filmes biodegradáveis. 2009. 93 p. (Mestrado em Ciências Moleculares), Universidade Estadual de Goiás, Anápolis, 2009.

19 GONTARD, N.; GUILBERT, S.; CUQ, J.L. Water and glycerol as plasticizers affect mechanical and water vapor barrier properties of an edible wheat gluten film. Journal of Food Science, Chicago, v.53, n.1, p.206-211, 1993.

20 HENRIQUE, C.M.; CEREDA, M.P.; SARMENTO, S.B.S. Características físicas de filmes biodegradáveis produzidos a partir de amidos modificados de mandioca. Ciência e Tecnologia de Alimentos, Campinas, v.28, n.1, p.231-240, 2008.

21 INSTITUTO ADOLFO LUTZ. Métodos físico-químicos para análise de alimentos. São Paulo, 2008. 1020 p.

22 KHURI, A. Z.; CORNELL, J. A. Response surface design and analysis. New York: Marcel Dekker, 1987. p.405.

23 KRIEGER, K.M.; DUVICK, S.A.; POLLAK, L.M.; WHITE, P.J. Thermal properties of corn starches extracted with different blending methods: micro blender and homogenizer. Cereal Chemistry, Saint Paul, v.74, n.5, p.553-555, 1997.

24 KRUEGER, B.R.; KNUTSON, C.A.; INGLETT, G.E.; WALKER, C.E. A differential scanning calorimetry study on the effect of annealing on gelatinization behavior on corn starch. Journal of Food Science, Chicago, v.52, n.3, p.715-718, 1987.

25 LEICA MICROSYSTEMS LIMITED. Leica application Suite Version 2.0.0. Solms, Germany, 2010. 1 CD.

26 LEITE, G.L.D.; SILVA, F.W.S.; JESUS, F.M.; COSTA, C.A.; GUANABENS, R.E.M.; GUSMÃO, C.A.G. Efeito da adubação orgânica, espaçamento e tamanho de rizoma-semente sobre artrópodes em mangarito Xanthosoma mafaffa Schott. Arquivos do Instituto Biológico, São Paulo, v.74, n.4, p.343-348, 2007.

27 LEONEL, M. Análise da forma e tamanho de grânulos de amidos de diferentes fontes botânicas. Ciência e Tecnologia de Alimentos, Campinas, v.27, n.3, p.579-588, 2007

28 LEONEL, M.; CEREDA, M.P. Caracterização físico-química de algumas tuberosas amiláceas. Ciência e Tecnologia de Alimentos, Campinas, v. 22, n. 1, p. 65-69, 2002.

29 MALI, S.; GROSSMANN, M.V.E.; GARCÍA, M.A.; MARTINO, M.N.; ZARITZKY, N.E. Barrier, mechanical and optical properties of plasticized yam starch films. Carbohydrate Polymers, v.56, p.129-135, 2004.

30 MALI, S.; GROSSMANN, M.V.E.; YAMASHITA, F. Filmes de amido: produção, propriedades e potencial de utilização. Semina: Ciências Agrárias, Londrina, v.31, n.1, p.137-156, 2010.

31 MONTEIRO, D.A; PERESSIN, V.A. Efeito do tamanho do rizoma-semente, da época e do local de plantio, na produção de rizomas de mangará. Bragantia, Campinas, v. 56, n.1, p.155-161, 1997.

32 MOURA, W. S. Extração e caracterização do amido do Hedychium coronarium e elaboração de filmes biodegradáveis. 2008. 81 p. Dissertação (Mestrado em Ciências Moleculares), Universidade Estadual de Goiás, Anápolis, 2008.

33 PÉREZ, E.E.; BREENE, W.M.; BAHNASSEY, Y.A. Variations in the gelatinization profiles of cassava, sagu and arrowroot native starches as measured with different thermal and mechanical methods. Starch/Stärke, Weinheim, v.50, n.2-3, p.7072, 1998. 
34 PEREZ-GAGO, M. B.; KROCHTA, J. M. Denaturation time and temperature effects on solubility, tensile properties, and oxygen permeability of whey protein edible films. Journal of Food Science, v.66, n.5, p.705-710, 2001.

35 PERONI, F.H.G. Características estruturais físico-químicas de amidos obtidos de diferentes espécies tropicais. 2003. 118 p. (Mestrado em Engenharia e Ciência de Alimentos) - Universidade Estadual Paulista "Júlio de Mesquita Filho", São José do Rio Preto, 2003.

36 SABATO, S.F. Aplicação da irradiação na formação de filmes comestíveis protéicos. 2000.107 p. Doutorado (Ciências na Área de Tecnologia Nuclear - Aplicação), Instituto de Pesquisas Energéticas e Nucleares, Universidade de São Paulo, São Paulo, 2000.

37 SARMENTO, A. Elaboração e caracterização de biofilmes a partir de gelatina reticulada. 1999.149 p. Dissertação (Mestre em Engenharia de Alimentos) - Faculdade de Engenharia de Alimentos, Universidade Estadual de Campinas, Campinas, 1999.

38 SHIMAZU, A.A.; MALI, S.; GROSSMANN, M.V.E. Efeitos plastificante e antiplastificante do glicerol e do sorbitol em filmes biodegradáveis de amido de mandioca. Semina, Londrina, v.28, n.1, p.79-88, 2007.

39 SINGH, N.; KAUER, M.; SANDHU, K.S.; GURAYA, H.S. Physicochemical, thermal, morphological and pasting properties of starches from some Indian Black gram (Phaseolus mungo L.) cultivars. Starch/Stärke, Weinheim, v.56, n.11, p.535544, 2004.

40 SOBRAL, P.J.do A. Influência da espessura de biofilmes feitos à base de proteínas miofibrilares sobre suas propriedades funcionais. Pesquisa Agropecuária Brasileira, Brasília, v.35, n.6, p.1251-1259, 2000.

41 STATSOFT Inc. Statistica (data analysis software system). Version 8.0. Tulsa, 2007. 1 CD-ROM.

42 VICENTINI, N. M. Elaboração e caracterização de filmes comestíveis à base de fécula de mandioca para uso em pós-colheita. 2003. 198 p. Tese (Doutorado em Agronomia - Área de Concentração em Horticultura), Universidade Estadual Paulista “Júlio de Mesquita Filho”, Botocatu, 2003.

43 VIEIRA, F.C. Efeito do tratamento com calor e baixa umidade sobre características físicas e funcionais dos amidos de mandioquinha-salsa (arracacia xanthorrhiza), de batata-doce (ipomoea batatas) e de gengibre (zingiber officinale). 2004. 122 p. Dissertação (Mestrado em Ciência e Tecnologia de Alimentos) - Escola Superior de Agricultura "Luiz de Queiroz", Universidade de São Paulo, Piracicaba, 2004.

44 VIGNEAU, E.; LOISEL, C.; DEVAUX, M.F.; CANTONI, P. Number of particles for the determination of size distribution from microscopic images. Powder Technology, v.107, p.243-250, 2000.

45 YOO, S.H.; JANE, J.I. Structural and physical characteristics of waxy and other wheat starches. Carbohydrate Polymers, Oxford, v.49, n.3, p.297-305, 2002.

\section{AGRADECIMENTOS}

À Fazenda Veadinho, localizada no perímetro rural do município de Uberlândia (MG) pela doação da matéria-prima (rizomas filhos do mangarito). À Universidade Estadual de Goiás e à Embrapa Agroindústria de Alimentos pelo apoio na realização das análises. À Coordenação de Aperfeiçoamento de Pessoal de Nível Superior (Capes) e à Fundação de Amparo à Pesquisa do Estado de Goiás (Fapeg) pelo suporte financeiro. 